\title{
Reflections on the Concept of Interoperability in Information Systems
}

\author{
Delfina Soares and Luis Amaral \\ ALGORITMI Research Center, University of Minho, Campus de Azurém, Guimarães, Portugal \\ $\{d s s$, amaral $\} @ d s i . u m i n h o . p t$
}

Keywords: Interoperability, Information Systems, Sociotechnical.

\begin{abstract}
Information systems interoperability is one of the main concerns and challenges of information systems managers and researchers, most of whom perceive and approach it on a pure or predominantly technological perspective. In this paper, we argue that a sociotechnical perspective of information systems interoperability should be adopted and we set out seven assertions that, if taken into consideration, may improve the understanding, management, and study of the information systems interoperability phenomenon.
\end{abstract}

\section{INTRODUCTION}

Interoperability became a popular term in recent years, catching the attention of professionals and researchers of the most various domains.

Despite of its current huge popularity, interoperability is not a recent term or concern. According to the Webster's Timeline History of Interoperability, this term has been used for decades in domains such as the military, transportation, healthcare, public safety, communications, and computer science (Parker, 2009). More recently, interoperability has become a central issue for professionals and researchers in the Information Systems (IS) domain.

Information systems interoperability is considered a mandatory issue for organizations' success, and even for their survival, in the current networked and globalized world, since it may increase organizations' agility and competitiveness, allow the provision of different and more integrated services, reduce operation costs, and improve organization's efficiency.

Besides being considered as something mandatory and beneficial, IS interoperability is also recognized as a complex, challenging, and difficult to achieve phenomenon. Indeed, many IS interoperability initiatives have failed to succeed and much of the money, effort, and time spent in them have not produced the expected results.

Many of the failures and problems found may be due to the inadequate interpretation and too narrow perspective that many practitioners and academics have on the IS interoperability concept.
Indeed, after a detailed and thorough literature review on the IS interoperability subject, as well as the analysis of multiple successful and unsuccessful IS interoperability practical cases, it is our conviction that the IS interoperability concept is many times mainly, or even exclusively, addressed and treated on a technical perspective. We argue that a pure technical perspective of IS interoperability may undermine and jeopardize the achievement of truly and adequate levels of interoperability between IS in organizations. Hence, a wider perspective of IS interoperability concept is needed, not only to improve the work of professionals as well as of researchers and academics in IS interoperability field. Along this paper we will expose some thoughts that support this argument.

This paper is organized as follows. After this introduction, in section two we reflect on the interoperability concept. By analyzing and comparing multiple definitions found for the term, we point out a set of key ideas underlying the concept of interoperability and highlight the existence of a certain misconception and misuse of the terms "interoperability" and "integration". In section three remarks are made concerning the interpretation of the interoperability concept in the IS domain. Based on the thoughts and remarks set out in sections 2 and 3, as well as on the experience and knowledge that we gained by conducting research studies on IS interoperability in public administration, we advance in section 4 seven assertions concerning the IS interoperability phenomenon. Final conclusions are presented in section 5 . 


\section{THE INTEROPERABILITY CONCEPT}

Despite being a term frequently used in current written and spoken discourses, the meaning of interoperability remains somewhat ambiguous and diffuse (Chen, 2005; CompTIA, 2004; Miller, 2000).

Two main aspects seem to justify the ambiguity regarding the concept of interoperability: (i) the existence of numerous and different definitions for the term, each of which highlighting a particular set of ideas and different perspectives that can be associated with it, and (ii) the lack of clarity that exists between the meaning ascribed to "interoperability" and to "integration", which is a term often used as synonym of interoperability. These two aspects will be discussed in more detail in the following subsections.

\subsection{Key Ideas Underlying the Interoperability Concept}

To better understand the concept of interoperability a wide range of definitions for this term was collected from the literature and analyzed (see Appendix).

As can be seen from Appendix, some of the definitions are very generic, defining interoperability in a very broadly way. This is the case, for example, of the definition found in Compact Oxford English Dictionary, where the term interoperable is defined as "able to operate together". Although this short definition exposes indeed the central idea underlying to the term interoperability (the idea of operating together), it is too generic. This excessive generality may easily lead to different understandings, depending on how the terms "operate" and "together" are interpreted. For example, if "operate" is interpreted as "run something" and "together" is interpreted as "physical proximity", then it is possible to say that in a situation where two software systems are both installed and running in the same machine there is interoperability between them, which does not correspond, in fact, to the meaning of this term.

Definition 8 , by the IEEE, which considers interoperability as "the ability of two or more systems or components to exchange information and use the exchanged information", introduces additional detail, that helps to prevent erroneous interpretations such as the one described above. In fact, the two requirements included in the IEEE definition (one requirement is the existence of an exchange and the other requirement is the fact that who gets what is exchanged uses it to do something) are aspects highlighted in most of the gathered definitions, being thus considered as two essential ideas underlying the interoperability concept. Definition 29 adds to the ability to exchange and use data the ability of one entity to use functionality of the other entities.

According to Chen (2005), a situation of interoperability is characterized by the idea of "acting on demand", i.e., one entity does something in response to a request received from another entity (the solicitor entity). Thus, there is only interoperability between two entities $\mathrm{A}$ and $\mathrm{B}$ if entity $\mathrm{A}$ is able to send its request to entity $\mathrm{B}$ and entity $\mathrm{B}$ is able to receive that request, to understand it and perform something that actually corresponds to the action that entity $\mathrm{A}$ intended to see executed by entity $\mathrm{B}$ in response to the request made.

Another requirement that seems essential for the existence of interoperability is related to the need of existing "understanding" between the entities that exchange the information. In fact, although two entities may be able to exchange information, there will only be effective interoperability between them if they have a shared understanding of the exchanged information. If this does not occur, although they could be able to interact, to exchange information, and use the exchanged information, the result of these interactions may not correspond to what would be expected. The need for the existence of a shared understanding between interoperating entities is explicit, for example, in definitions 5, 23, and 25 of Appendix.

According to definitions 19, 24, and 26, another prime characteristic of interoperability is the fact that each of the involved entities should be able to operate without having to know details about the internal mode of operation of the other entities and without having to do a significant effort to change its internal mode of operation.

Two additional ideas characterizing a scenario of interoperability are still evidenced by some definitions. One such idea is exposed in definitions $4,18,22$, and 28 and refers to the fact that entities should act in order to achieve a common goal or objective. As regarded by Chen (2005), we can only achieve true interoperability if the action of participating entities contributes to the achievement of a common goal, which is the ultimate goal intended for the outlined interoperation procedure.

A final key idea is implicit in definitions $3,8,10$, $11,12,13,14,15,16,17,18,20,21$, and 28 and refers to the fact that the involved entities are usually 
heterogeneous entities (they were created or developed in an isolated and independent way) that operate autonomously. The preservation of this autonomy of operation is fundamental and thus the ability to create interoperability between entities must be achieved with minimum interference in the autonomy of each one of them.

The ideas pointed out in previous paragraphs highlight a set of key aspects underlying the interoperability concept. Given this set of key ideas - "two or more entities", "operating together", "shared understanding", "effortless operation", "operation with a common goal", "autonomy", "heterogeneity" - we conceive interoperability as the ability of two or more heterogeneous and autonomously operating entities to exchange and use information or functionality of each other, correctly, conveniently, and without a significant effort, in order to contribute to the achievement of a specific purpose.

According to these ideas, the use of the term interoperability refers to situations where entities developed in isolation, operating independently, and exhibiting disparate characteristics are able to operate jointly to achieve an overall objective, while maintaining their autonomy and heterogeneity and without having to know the specific characteristics of the other entities with which they interoperate.

\subsection{Interoperability versus Integration}

As mentioned before, another factor contributing to the ambiguity surrounding the understanding of the concept of interoperability refers to the absence of clarity between the terms interoperability and integration, which are often used in an indiscriminate and undifferentiated way.

According to the IEEE dictionary, integration can be defined as "the process of combining software components, hardware components or both in an overall system" or as "the merger or combining of two or more lower-level elements into a functioning and unified higher-level element with the functional and physical interfaces satisfied" (IEEE, 1997: p. 537). The idea of fusion and unification set out in these definitions is also evident in the definition of Merriam-Webster online dictionary, where "integrate" is defined as "to form, coordinate, or blend into a functioning or unified whole", "to unite with something else" or "to incorporate into a larger unit" (integrate, 2014).

While in a situation of interoperability participating entities remain autonomous and independent, so that any of them can be easily replaced by another with similar specification without changing the functionality of the overall system, in a situation of integration participating entities are assimilated into a larger whole (Busson and Keravel, 2005; Chen et al. 2008; Dodd et al., 2003). This may cause serious difficulties and lead to a loss of functionality of the overall system if any entity changes or needs to be replaced (Busson and Keravel, 2005). Integration is thus considered as extending beyond interoperability, in that, unlike interoperability, it involves a degree of functional dependency between the involved entities (Busson and Keravel, 2005; Chen et al. 2008; EC, 2008; Faughn, 2002; Panetto and Molina 2008). In this sense, it can be said that a family of integrated entities must be interoperable, but interoperable entities do not necessarily have to be integrated (Chen and Doumeingts, 2003; Chen et al. 2008; Panetto and Molina 2008).

Table 1 highlights three differences usually cited between interoperability and integration.

Table 1: Characteristics of Interoperability and Integration.

\begin{tabular}{|c|c|}
\hline Interoperability & Integration \\
\hline Coexistence & Unification \\
\hline Autonomy & Assimilation \\
\hline Loosely coupled & Tightly coupled \\
\hline
\end{tabular}

Unlike what happens in full integration, in which the connections between the entities are rigid and fixed, in interoperability the connections between entities are more flexible, being easy to establish and change (Aubert et al., 2003). For this reason, interoperability assumes a relevant role in complex and uncertain environments, where involved actors and relations are unpredictable and dynamic. Indeed, it is increasingly difficult to fully anticipate the number and kind of interconnections in which a given entity (be it a software component, an application, an information system, an organization, or whatever kind of entity) will be involved in the future (Carney and Oberndorf, 2004).

As curiously noted by Sasovova et al. (2001), the existence of high levels of integration between the internal systems of an organization may constrain a set of high level strategic decisions, such as the decision to sell or dispose an organizational unit or to outsource some business activities or services. In situations like those, if the internal systems of the organization are tightly integrated, a significant effort will be needed to disintegrate them. According to the same authors, disintegration efforts may constitute an even harder and risky task than the task 
of integrating them. Thus, contrarily to the most common thought, the existence of a high level of integration between systems may not be the most appropriate solution for any given context (Aubert et al., 2003; Lee and Myers, 2004; Sasovova et al., 2001; Pavlou and Singletary, 2002), since it may significantly compromise the agility, flexibility, and responsiveness of organizations.

\section{INTEROPERABILITY IN INFORMATION SYSTEMS}

In the previous section we presented a set of basic ideas underlying the concept of interoperability, independently of the domain in which this term is used. However, a full and rich meaning of the term is only achieved when it is analyzed and interpreted in its context of use. This means that when talking about interoperability between information systems it is fundamental to understand the implications that the IS context can bring to the way interoperability concept is interpreted and treated.

Different perspectives on information systems can be found in literature. One of such perspectives envisages IS as sociotechnical systems, i.e., systems that encompass elements of social and technological nature.

The coexistence of these two elements is reflected in some IS definitions, such as the one advanced by Visala (1991: 349) where information system is defined as "a social and technical system that models and provides information about a universe of discourse", or in the definition presented by Alter (1992: 7) for whom "information system is a system that consists of people, work practices, technology, and information, which interact in order to accomplish organizational goals". The same perspective is shared by Amaral (1994) that considers information system as being an abstraction that results from observing an organization from an information perspective, as well as the human, organizational and technological resources involved in the information gathering, storing, processing and delivering.

Three central ideas emerge from the above definitions, namely that an Information System:

i. is an abstraction of the organization, which means that it is something inherent and intrinsic to the organization (i.e., if there exists an organization, there exists its information system); ii. is, in its essence, a system of social and human activity;

iii. is, in its existence, a technologically supported system (information technologies are increasingly supporting the organization information system).

In this sense, as illustrated in Figure 1, people, processes and technologies are constituting elements of the information system of an organization: information in the organization is handled by people to run a set of organizational processes that contribute to the achievement of organization's objectives and to the fulfillment of organization's mission; the execution of the organizational processes is supported and facilitated by the use of technologies.

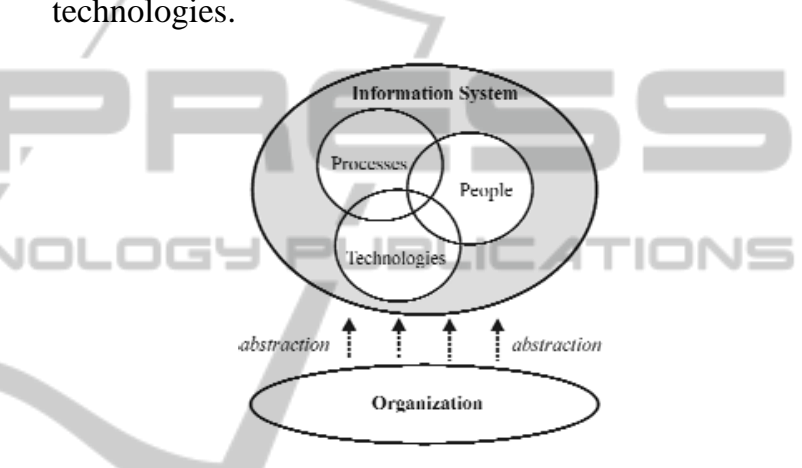

Figure 1: Information System as Sociotechnical System.

The importance that social and organizational issues assume in the design, development, management, adoption, and use of information systems has long been documented in the literature. According to a survey conducted by Doherty and King (1998), only $10 \%$ of existing faults and failures in IS development projects were due to technological issues, with the remaining $90 \%$ attributed to social and organizational issues. These issues tend to be even more prevalent and determinant in inter-organizational IS, since the number and diversity of technologies, organizational processes, people and interests involved is bigger (Luna-Reyes et al., 2005).

To considerer information systems as sociotechnical systems has an immediate consequence for the discussion set forth in this paper which is: the phenomenon of "information systems interoperability" should be perceived, implemented, managed, and studied in a sociotechnical perspective (Figure 2). In other words, the process of achieving true and effective interoperability between information systems requires more than the mere connection, understanding and joint operation capacity of the technological elements of the 
information systems; it requires that this connection, understanding and joint operation capacity be extended to the other relevant elements of information systems: processes and people.

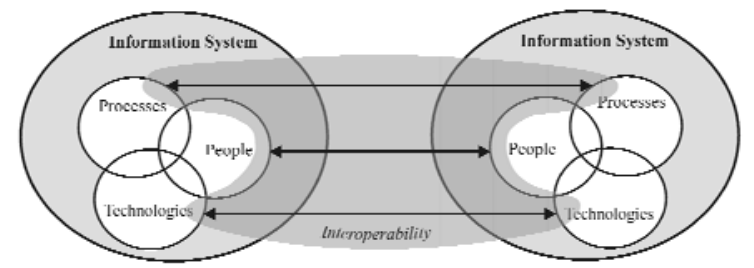

Figure 2: IS Interoperability: A Sociotechnical Perspective.

Indeed, as stressed in Reach (2004: 6), "ultimately, interoperability is the result of human to human agreements; given a human agreement to be interoperable, technology can help implement that agreement but no amount of technology can achieve true interoperability in the absence of human agreement". Hence, while the importance of the technological component is undeniable, human and social components of this phenomenon should not be ignored. This view is also shared by Dodd et al. who consider that interoperability starts first with people. As the authors recall "sometimes just getting the right people in the room does wonders for interoperability, trust and sharing" (Dodd et al., 2003: 12).

\section{ASSERTIONS ABOUT INFORMATION SYSTEMS INTEROPERABILITY}

The thoughts brought out in previous sections concerning the concepts of interoperability and of information systems, and the knowledge that resulted from previous research studies we undertook on interoperability in public administration information systems, led us to formulate seven assertions about the phenomenon of IS interoperability, which we believe are relevant and should frame the way this phenomenon may be viewed, managed and studied.

\section{A1 - IS Interoperability: A Collective Phenomenon}

IS interoperability is a phenomenon that involves at least two but most of the times many entities. Each of the involved entities assumes an important role in it. As so, IS interoperability initiatives and efforts must be planned, developed, managed and studied as collective initiatives or efforts. This sets new challenges to organizations, managers and researchers and requires from them a new mindset of cooperative and collaborative work.

\section{A2 - IS Interoperability: Not an Integration Phenomenon}

As argued in section 2.2, although often used interchangeably, interoperability and integration terms refer to different phenomena. Due to unsuccessful past experiences of IS integration, many of them associated with the implementation of ERP systems, a misconception of interoperability and its association with integration initiatives may generate enormous difficulties and resistances to accept the IS interoperability phenomenon. For this reason, it seems fundamental to demystify the difference between interoperability and integration.

\section{A3 - IS Interoperability: A Federalist Phenomenon}

In section 2.1 the preservation of the entities' autonomy of operation was mentioned as a key idea underlying the concept of interoperability. This idea reflects the federalist nature that should characterize interoperability (Chen, 2005; Daclin, 2005; Doumeingts and Chen, 2003; Tsagkani, 2005). Federalism is described by Schwarzenbacher and Wagner (2005) as the structural and organizational principle by which separate and autonomous entities combine efforts to reach a global operation, while preserving as much as possible, their individuality, autonomy, and independence.

Indeed, in an interoperability scenario, despite involved entities should be able to operate together to promote the image of a whole, their independence and autonomy should be maintained (Lueders, 2005), thus allowing them to preserve their own identity and way of working (Daclin, 2005; Lueders, 2005).

This federalist nature represents a valuable characteristic of interoperability since it can avoid or mitigate many difficulties and resistances that could arise if entities would have to change significantly their way of operating or their information systems.

\section{A4-IS Interoperability: Not a "Limiter of Freedom" Phenomenon}

Due to the misconception pointed out in assertion A2, some entities view interoperability as something that will limit their freedom of choice and action. It is common to think that "to be able to work and operate jointly" may imply "to be subject to major changes and to have to adopt new data formats, semantics, procedures, and technologies". This is not, however, the intent underlying interoperability. 
As stressed in assertion A3, in an interoperability scenario each entity should preserve its autonomy and independence of functioning. In other words, each entity should be free to organize its internal data, processes and technologies as it wants, as soon as it agrees and follows a set of rules and standards at multiple levels that allows it to externally connect to, exchange data, and understand the data exchanged with other entities.

Although some entities may also argue that the need to adopt and follow a predefined specific set of standards to be able to interoperate is also something limiting of their freedom, this seems to us an excessive argument. Actually, a minimum set of shared rules and norms between the parts is expected to exist, otherwise it would be impossible to achieve any kind of collective action.

Hence, it is fundamental to understand that the federalist nature of the interoperability phenomenon reduces to a minimum the lack of freedom of the entities, since it can increase interoperability acceptance.

\section{A5 - IS Interoperability: Not an Exclusively Technological Phenomenon}

The existence of interoperability between information systems requires undoubtedly the ability of those systems to interoperate at a technological level. However, as argued, IS are sociotechnical systems, encompassing other elements besides the technological ones. Additionally, as pointed in assertion A1, interoperability is a collective phenomenon, that may involve multiple entities, each of them with its organizational, cultural, human and technological legacy. For this reason, the challenges around IS interoperability phenomenon are huge, complex and diverse, tending to be even more related to organizational, behavioral, and cultural issues than to technical issues. As such, it becomes essential to demystify the idea commonly shared in literature and practice that interoperability is only, or essentially, a technological challenge.

\section{A6 - IS Interoperability: A Cultural, Social and Human Phenomenon}

Interoperability begins and ends with people. Ultimately, it is people, with their values, their perceptions, their beliefs and their experiences that dictate the success of interoperability between IS: it is people who think, manage and coordinate the phenomenon of interoperability; it is people who define, agree and adopt standards and rules essential for the achievement of interoperability, and it is people who fit and align systems and their interpretative contexts so that the necessary understanding for the existence of interoperability is achieved. It is does fundamental to take a broad perspective, including cultural, social and human aspects, when studying, implementing, and managing information systems interoperability.

\section{A7 - IS Interoperability: A Communication, Negotiation and Diplomacy Phenomenon}

Since IS interoperability is a collective phenomenon, which depends largely on the existence of standards and agreements between all the involved parts, the implementation of interoperability between IS constitutes unavoidably a phenomenon of communication, negotiation and diplomacy. Therefore, communication, negotiation and diplomacy skills are key ingredients in order to define a consensual set of norms and rules that are broadly accepted and adopted by the parties.

\section{CONCLUSIONS}

The assertions set out in last paragraphs derive from and reflect the widen vision that we have on the information systems concept - information systems as sociotechnical systems -, which consequently led us to interpret IS interoperability in a sociotechnical perspective.

This kind of interpretation is not so commonly found in the literature as we thought. Indeed, most of the works on IS interoperability treat this phenomenon in a pure technological perspective. While calling it IS interoperability, many of the works end by focusing their attention on IT interoperability and applications interoperability. In our opinion, this is not the same thing. The reflections presented in this paper intend precisely to call the attention to this fact, and serve as basis for further discussions on this.

The seven assertions enunciated highlight what seems to be crucial issues on the phenomenon of IS interoperability and constitute new insights on how this phenomenon should be interpreted.

To be aware of these issues seems to be fundamental for those who are involved in IS interoperability implementation and management projects as well as for those that study, research and try to better understand the phenomenon of interoperability between information systems. To have only a partial view of the IS interoperability phenomenon may threaten the success of many IS interoperability efforts. Therefore, it is our conviction that these assertions should reap the 
attention and penetrate the mindset of those involved in this area and should be taken into account when implementing and researching in the area of IS interoperability.

Additional reflections and discussion are needed, and future work should be done in order to understand the value of each of those assertions and their consequences for IS interoperability practitioners and researches communities.

\section{REFERENCES}

Alter, S., 1992. Information Systems: A Management Perspective, Reading: Addison-Wesley.

Amaral, L., 1994. PRAXIS: Um Referencial para o Planeamento de Sistemas de Informação. $\mathrm{PhD}$ Thesis, University of Minho, Braga.

Aubert, B., Vandenbosch, B., and Mignerat, M., 2003. Towards the Measurement of Process Integration. Available: http://expertise.hec.ca/gresi/wp-content /uploads/3013/02/cahier0306.pdf (29 Sept 2013).

Busson, A. and Keravel, A., 2005. Interoperable government providing services: key questions and solutions analysed through 40 case studies collected in Europe. In Proceedings of the eGov-Interop'05 Conference, 23-24 February, Geneva, Switzerland.

Carney, D. and Oberndorf, P., 2004. Integration and Interoperability Models for Systems of Systems. Available: http://www.sei.cmu.edu/library/assets

/sstcincose.pdf (4 Dec 2013).

Chen, D., 2005. Practices, principles and patterns for interoperability. Report of INTEROP NoE, FP6 Network of Excellence - Deliverable 6.1, May 2005.

Chen, D. and Doumeingts, G., 2003. European initiatives to develop interoperability of enterprise applications basic concepts, framework and roadmap. Annual Reviews in Control 27(2): 153-162.

Chen, D., Doumeingts, G., and Vernadat, F., 2008. Architectures for enterprise integration and interoperability: Past, present and future. Computers in Industry 59 (7): 647-659.

CompTIA, 2004. European Interoperability Framework ICT Industry Recommendations. White Paper.

Daclin, N., 2005. Contribution to a methodology to develop interoperability of enterprise applications. In Proceedings of the INTEROP-ESA'05, 23-25 February, Geneva, Switzerland.

Dodd, J., Peat, B., Mayo, D., Christian, E., and Webber, D., 2003. Interoperability Strategy: Concepts, Challenges, and Recommendations. Industry Advisory Council.

Doherty, N. and King, M., 1998. The importance of Organisational Issues in Systems Development. Information Technology \& People 11(2): 104-123.
EC, 2008. Draft document as basis for EIF 2.0. Draft for public comments. European Commission.

Faughn, A., 2002. Interoperability: Is it Achievable? Program on Information Resources Policy. Available: http://pirp.harvard.edu/pubs_pdf/faughn/faughn-p026.pdf (2 Dec 2013).

IEEE, 1997. The IEEE Standard Dictionary of Electrical and Electronics Terms. 6th Edition. New York: Institute of Electrical and Electronics Engineers.

integrate, 2014. In Merriam-Webster.com. Available: http://www.merriam-webster.com/diction ary/integrate (14 Jan 2014).

Lee, J. and Myers, M., 2004. The Challenges of Enterprise Integration: Cycles of Integration and Desintegration Over Time. In Proceedings of the 25th International Conference on Information Systems (ICIS 2004), December 2004, Washington DC, USA.

Lueders, H., 2005. Interoperability and Open Standards for eGovernment Services. In Proceedings of the eGov-Interop'05 Conference, 23-24 February, Geneva, Switzerland.

Luna-Reyes, L., Zhang, J., Gil-Garcia, R., Cresswell, A., 2005. Information systems development as emergent socio-technical change: a practice approach. European Journal of Information Systems 14(2): 93-105.

Miller, P., 2000. Interoperability: What is it and Why should I want it?. Available: http://www.ariadne.ac.uk /issue24/interoperability (29 Sep 2013).

Panetto, H. and Molina A., 2008. Enterprise integration and interoperability in manufacturing systems: Trends and issues. Computers in Industry 59 (7): 641-646.

Parker, P., 2009. Interoperability: Webster's Timeline History, 1983-2007. California: ICON Group Int.

Pavlou, P. and Singletary, L., 2002. Empirical Study of Stakeholders' Perceived Benefits of Integration Attributes for Enterprise IT Applications. In Proceedings of the 8th Americas Conference on Information Systems (AMCIS 2002).

Reach, 2004. Reach Interoperability Guidelines: Interoperability Theory and Practice. Available: http://sdec.reach.ie/rigs/rig0012/pdf/rig0012_v0_41.pd f (9 May 2005).

Sasovova, Z., Heng, M. and Newman, M., 2001. Limits to Using ERP Systems. In Proceedings of the 7th Americas Conference on Information Systems (AMCIS 2001), Paper 221: 1142-1146.

Schwarzenbacher, K. and Wagner, J., 2005. The Federative Principle in Business Architecture. In Proceedings of the INTEROP-ESA'05, 23-25 February, Geneva, Switzerland.

Tsagkani, C., 2005. Inter-Organisational Collaboration on the Process Layer. In Proceedings of the INTEROPESA'05, 23-25 February, Geneva, Switzerland.

Visala, S., 1991. Broadening the Empirical Framework of Information Systems Research. In Nissen, H., Klein, H. and Hirschheim, R. (Eds.), Information Systems Research: Contemporary Approaches \& Emergent Traditions: 347-364. Amsterdam: North-Holland. 


\section{APPENDIX}

\section{LIST OF DEFINITIONS OF INTEROPERABILITY}

1. Interoperable - adjective (of computer systems or software) able to operate in conjunction. Compact Oxford English Dictionary of Current English, Third Edition, Oxford University Press, 2005.

2. Interoperability - characteristic that allows the connection and jointly of multiple computers. Grande Dicionário da Língua Portuguesa,Porto Editora, 2004.

3. Interoperability is the ability to use resources from diverse origins as if they had been designed as parts of a single system.

Bollinger, T., 2000. A Guide to Understanding Emerging Interoperability Technologies. MITRE

(http://www.mitre.org/work/tech_papers/tech_papers_00/bollinger_interoperability/bollinger_interop.pdf).

4. (A) Interoperability is the ability of systems, units, or forces to provide services to and accept services from other systems, units, or forces and to use the services so exchanged to enable them to operate effectively together.

(B) The condition achieved among communications-electronics systems or items of communications-electronics equipment when information or services can be exchanged directly and satisfactorily between them and/or their users. DOD-NATO JP 1-02 (http://www.fas.org/irp/doddir/dod/jp1_02.pdf).

5. The ability of one system to receive and process intelligible information of mutual interest transmitted by another system. [JINTACCS 74] cited in Kasunic, M. and Anderson, W., 2004. Measuring Systems Interoperability: Challenges and Opportunities, Carnegie Mellon University.

6. Interoperability is the ability of information systems to operate in conjunction with each other encompassing communication protocols, hardware, software, application, and data compatibility layers.

ICH Glossary of Terms (http://www.ichnet.org/glossary.htm).

Poler, R., Tomás, J. and Velardi, P., 2005. Interoperability Glossary, INTEROP NoE, Deliverable 10.1, Version $1 B$.

7. Enabling different systems to work together and exchange data

CETIS Acronyms and Glossary (http://www.cetis.ac.uk/members/enterprise/glossary)

8. (A) Interoperability is the ability of two or more systems or components to exchange information and to use the information that has been exchanged.

(B) The capability for units of equipment to work together to do useful functions.

(C) The capability, promoted but not guaranteed by joint conformance with a given set of standards, that enables heterogeneous equipment, generally built by various vendors, to work together in a network environment.

(D) The ability of two or more systems or components to exchange information in a heterogeneous network and use that information.

IEEE, 1997. The IEEE Standard Dictionary of Electrical and Electronics Terms. 6th Edition. New York: Institute of Electrical and Electronics Engineers.

9. Interoperability is the ability to exchange information and mutually to use the information which has been exchanged. Council Directive of 14 May 199 on the legal protection of computer programmes (91/250/EEC).

10. Interoperability is the ability of independent, distributed software components to operate together as part of a larger system.

http://www.canri.nsw.gov.au/glossary.html

11. Interoperability is the ability of computer systems made by different manufacturers to operate with one another. http://www.iomega.com/europe/support/english/documents/11240e.html

12. Interoperability is the ability to operate and exchange information in a multivendor/multiproduct network. http://www.networkcables.com/i.htm

13. Interoperability is the ability of software and hardware to communicate and function across multiple machines, under multiple vendor formats.

http://dli.grainger.uiuc.edu/glossary.htm

http://www.aot.state.vt.us/CaddHelp/cadd/glossary/gloss_i.htm

14. Interoperability is the ability of a network to operate with other networks, such as two systems based on different protocols or technologies.

http://www.roadtripamerica.com/dashboarding/glossary.htm 
15. Interoperability is the ability of different types of databases, applications, operating systems, and platforms to function in an integrated manner.

http://www.dddmag.com/scripts/glossary.asp

16. Interoperability is the ability of one manufacturer's computer equipment to operate alongside, communicate with, and exchange information with another vendor's dissimilar computer equipment.

http://www.networkbuyersguide.com/search/105487.htm

17. Interoperability is the ability to exchange and use information (usually in a large heterogeneous network made up of several local area networks).

http://www.hyperdictionary.com/dictionary/interoperability

http://www.cogsci.princeton.edu/cgi-bin/webwn

18. Interoperability is the ability of different types of computers, networks, operating systems, and applications to work together effectively, without prior communication, in order to exchange information in a useful and meaningful manner.

Dublin Core Metadata Glossary (http://library.csun.edu/mwoodley/dublincoreglossary.html).

19. Interoperability is the ability of content, a subsystem or system to seamlessly work with other systems, subsystems or content via the use of agreed specifications/standards. http://www.tasi.ac.uk/glossary/glossary_technical.html

20. Interoperability is the ability of heterogeneous systems and networks to communicate and cooperate through specified standards. http://info.louisiana.edu/dept/glosi.html

21. Interoperability is the ability of equipment from multiple vendors to communicate using standardized protocols. http://www.nationaldatamux.com/G50001.htm

22. Interoperability may be defined as a process that effectively links two or more systems (marketplaces or other service providers) or organizations in a partial or fully transparent manner (for users).

Scriven, G., "Interoperability in Australian Government E-Procurement - Strategy versus Reality", 7th Pacific Asia Conference on Information Systems, Adelaide, South Africa, 2003.

23. Interoperability is achieved only if the interaction between two systems can, at least, take place at the three levels: data, resource and business process with the semantics defined in a business context.

Chen, D. and G. Doumeingts (2003). "European initiatives to develop interoperability of enterprise applications:- basic concepts, framework and roadmap." Annual Reviews in Control, 27(2): 153-162.

24. Interoperability is the capability to communicate, execute programs, or transfer data among various functional units in a manner that requires the user to have little or no knowledge of the unique characteristics of those units. ISO 19119 Services.

25. Interoperability is the ability to share and exchange information using common syntax and semantics to meet an application-specific functional relationship through the use of a common interface. ISO16100.

26. In a purely technological perspective, interoperability concerns the ability of two or more ICT assets (hardware devices, communications devices or software components) to easily or automatically work together. In a business perspective, the previous definition expands to include the ability of two or more business processes, or services, to easily or automatically work together.

CompTIA, European Interoperability Framework - ICT Industry Recommendations (White Paper), 2004.

27. Interoperability is the ability of ICT systems and of the business processes they support to exchange data and to enable sharing of information and knowledge.

IDABC, European Interoperability Framework for pan-European eGovernment Services, 2004.

28. Interoperability is the ability of disparate and diverse organizations to interact towards mutually beneficial and agreed common goals, involving the sharing of information and knowledge between the organizations via the business processes they support, by means of the exchange of data between their respective information and communication technology (ICT) systems.

IDABC, European Interoperability Framework for pan-European eGovernment Services, 2008.

29.Interoperability is defined as the ability to communicate, execute programs, or transfer data among various functional units due to the use of common languages and protocols, requiring little or no knowledge of the user about the specific features of these units.

APDSI, 2011, Glossário da Sociedade da Informação (http://www.apdsi.pt/uploads/news/id432/gloss\%C3\%

Alrio\%da\%20si\%20-\%20vers\%C3\%A3o\%202011.pdf) 